\title{
Segment-specific association between cervical pillar hyperplasia (CPH) and degenerative joint disease (DJD) Maja Stupar* ${ }^{* 1}$ and Cynthia K Peterson ${ }^{\dagger 2}$
}

Address: ${ }^{1}$ Division of Clinical Education, Canadian Memorial Chiropractic College, 6100 Leslie Street, Toronto, ON M2H 3J1, Canada and 2Department of Radiology, Canadian Memorial Chiropractic College, 6100 Leslie Street, Toronto, ON M2H 3J1, Canada

Email: Maja Stupar* - mstupar@cmcc.ca; Cynthia K Peterson - cpeterson@cmcc.ca

* Corresponding author †Equal contributors

Published: 13 September 2006

Chiropractic \& Osteopathy 2006, 14:21 doi:|0.||86/|746-|340-|4-2|

Received: 27 January 2006

Accepted: 13 September 2006

This article is available from: http://www.chiroandosteo.com/content/14/I/2I

(c) 2006 Stupar and Peterson; licensee BioMed Central Ltd.

This is an Open Access article distributed under the terms of the Creative Commons Attribution License (http://creativecommons.org/licenses/by/2.0), which permits unrestricted use, distribution, and reproduction in any medium, provided the original work is properly cited.

\begin{abstract}
Background: Cervical pillar hyperplasia $(\mathrm{CPH})$ is a recently described phenomenon of unknown etiology and clinical significance. Global assessment of pillar hyperplasia of the cervical spine as a unit has not shown a relationship with degenerative joint disease, but a more sensible explanation of the architectural influence of $\mathrm{CPH}$ on cervical spine biomechanics may be segment-specific.
\end{abstract}

Objective: The objective of this study was to determine the level of association between degenerative joint disease (DJD) and cervical pillar hyperplasia (CPH) in an age- and gendermatched sample on a [cervical spine] by-level basis.

Research Methods: Two-hundred and forty radiographs were collected from subjects ranging in age between 40 and 69 years. The two primary outcome measures used in the study were the segmental presence/absence of cervical pillar hyperplasia from $\mathrm{C} 3$ to $\mathrm{C} 6$, and segment-specific presence/absence of degenerative joint disease from $\mathrm{Cl}$ to $\mathrm{C} 7$. Contingency Coefficients, at the $5 \%$ level of significance, at each level, were used to determine the strength of the association between $\mathrm{CPH}$ and DJD. Odds Ratios (OR) with their $95 \%$ Confidence Intervals $(95 \% \mathrm{Cl})$ were also calculated at each level to assess the strength of the association.

Results: Our study suggests that an approximately two-to-one odds, or a weak-to-moderate correlation, exists at $\mathrm{C} 4$ and $\mathrm{C} 5 \mathrm{CPH}$ and adjacent level degenerative disc disease (DDD); with the strongest (overall) associations demonstrated between C4 CPH and C4-5 DDD and between C5 $\mathrm{CPH}$ and C5-6 DDD. Age-stratified results demonstrated a similar pattern of association, even reaching the initially hypothesized $\mathrm{OR} \geq 5.0(95 \% \mathrm{Cl}>1.0)$ or "moderately-strong correlation of $C \geq .4(\mathrm{p} \leq .05)$ " in some age categories, including the 40-44, 50-59, and 60-64 years of age subgroups; these ORs were as follows: $\mathrm{OR}=5.5(95 \% \mathrm{Cl}$ I.39-2I.59); OR $=6.7(95 \% \mathrm{Cl} \mathrm{I.65-}$

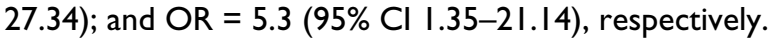

Conclusion: Our results suggest that $\mathrm{CPH}$ has around two-to-one odds, that is, only a weak-tomoderate association with the presence of DJD (DDD component) at specific cervical spine levels; therefore, CPH may be but one of several factors that contributes (to a clinically important degree) to the development of DJD at specific levels in the cervical spine. 


\section{Background}

Cervical pillar hyperplasia $(\mathrm{CPH})$ is a radiological finding which first made its appearance in the literature less than 30 years ago [1-4]. Its etiology and clinical significance are presently unknown; nevertheless, studies have shown that $\mathrm{CPH}$ is a frequently overlooked etiology for the loss of the cervical lordosis [2,3]. While these findings were disputed by several authors [5-9], other consequences of cervical pillar hyperplasia are not known at the present time. It has been theorized that the architectural difference that the presence of hyperplasia introduces into the cervical pillar may cause segmental biomechanical changes and may lead to a higher prevalence of degenerative joint disease (DJD) at the hyperplastic or adjacent cervical levels. The clinical significance of this phenomenon, if found to be related to degenerative joint disease, should prompt an astute clinician into evaluating the articular pillars on all cervical spine radiographs - particularly because there could be a chance that the patient may develop degeneration at the specific cervical levels and may experience associated neck pain. The architecture of the cervical pillars cannot be modified by conservative therapy; therefore, clinicians should be aware that some of the symptoms may be attributed to degeneration and may influence the expected prognosis of the management of neck pain in those particular patients.

Currently, it is unknown whether the architecture of the articular pillars has a clinically important effect on segmental biomechanics and subsequent degeneration. The axis around which segmental flexion/extension occurs is principally influenced by the orientation of the facet joint in relation to the horizontal plane $[10,11]$. A more horizontal facet in comparison to the plane of the superior endplate will shift the instantaneous center of rotation anteriorly, resulting in an increased load on the intervertebral disc (with changes in lateral flexion motion) and an increased risk of anterolisthesis [10,12-14]. A straightening of the cervical curve, possibly caused by $\mathrm{CPH}[2,3]$, results in a redistribution of the loads, favouring the facet joints, and therefore increasing the load on the associated intervertebral disc. Although this has only been demonstrated in a mechanical model, the evidence to-date suggests that an increase of the stress-load on the intervertebral disc locally may enhance the degenerative process in the intervertebral compartment [15]. The possibility that a change in architecture may change the biomechanics of the cervical spine [16] has led to the hypothesis that individuals who have $\mathrm{CPH}$ may be predisposed to more biomechanical stress, as is involved in the predominantly accepted theory of the development of degenerative joint disease.

In our preliminary study, although we found no clinically important difference between the global presence/ absence of cervical pillar hyperplasia and prevalence of DJD, a more sensible explanation of the architectural influence of $\mathrm{CPH}$ on cervical spine biomechanics may be segment-specific, meaning that a hyperplastic pillar at a specific cervical level may be related to a higher prevalence of DJD at that specific level and/or one segment above or below. We therefore recommended that follow-up research evaluate the segment-specific contribution of pillar hyperplasia to the development and severity of DJD, because a segmental effect on the biomechanics of the cervical spine is more probable. We assume that the degenerative processes would be a result of the cervical pillar hyperplasia and not the opposite, since $\mathrm{CPH}$ has been observed at all ages.

The cervical spine experiences a combination of active mobility and loading stresses [17], and is therefore, a region of the spine that is frequently affected by progressive degenerative processes. These processes lead to the condition called "degenerative disc disease" (DDD) characterized by narrowing of the intervertebral discs, development of osteophytes, intercalary bones and surrounding subchondral sclerosis [18-21]. Similar radiographic findings affecting the facet and uncovertebral joints can also be present in facet arthrosis and uncovertebral arthrosis, respectively $[18,19,21]$.

Several grading systems have been developed to determine the degree of degeneration radiographically, using signs of subchondral sclerosis, joint space irregularity, decreased joint space and anterior and/or posterior osteophyte formation $[19,22]$. DJD, osteoarthrosis, or cervical spondylosis, are terms attributed to one or a combination of these findings affecting the disc (DDD), uncovertebral, and facet joints (uncovertebral and facet arthrosis) at a particular spinal segment.

DJD is a common, age-related, multi-factorial condition with several theorized etiologies including metabolic, mechanical, inflammatory, and genetic components [18$20,23]$. This condition affects all joints, especially those that experience chronic biomechanical stresses such as frequent repetitive use and strain, previous trauma and frequent weight-bearing [19].

The clinical implications of these degenerative processes may include: limitation of head and neck mobility, with or without pain; possible intervertebral foramen encroachment and central canal stenosis, which can result in nerve root or spinal cord compression (radiculopathy and myelopathy respectively) [20,24,25]; and, although less common, extensive anterior osteophytosis can lead to dysphagia or even vocal fold paralysis [26]. Some controversy exists in the literature with regard to whether radiological findings are related to the patient's symptoms to a 
clinically important degree. One long-term follow-up study [27] found that patients' symptoms correlate with radiographic findings; however, the majority of authors to-date found only a weak relationship between radiographic degenerative changes and pain [28-31].

The presence of DJD is often confirmed using plain film radiographic findings, with the lateral view being the most informative [20]. The reliability of determining the severity of DJD on plain film radiographs in the cervical spine has not been established, but the reliability of detecting the presence or absence of DJD has a substantial-to-almost-perfect agreement when assessing the presence/absence of intervertebral disc narrowing, osteophyte formation, zygapophyseal joint, and uncinate process degeneration [32].

Since the relationship between cervical spine DJD and $\mathrm{CPH}$ has only been studied 'globally' (i.e. CPH was judged to be generally present/absent within the cervical spine as a whole, regardless of whether hyperplastic pillars were detected at one or more levels from C3 to C6), the etiology and clinical relevance of $\mathrm{CPH}$ remain unknown. The purpose of this paper, therefore, is to determine if there is a clinically important association $(\mathrm{OR} \geq 5.0$ and $\mathrm{C} \geq .4$ ) between cervical pillar hyperplasia $\mathrm{CPH}$ ) and degenerative joint disease (DJD) at specific cervical levels, in an age- and gender-matched sample, and how strong this relationship is between the two conditions, on a by level basis.

\section{Methods}

\section{Research Design}

This is an association-etiological type of study design.

\section{Research Hypothesis}

We hypothesized that there would be a clinically important association of $\mathrm{C} \geq .4(\mathrm{p} \leq .05)$ and/or $\mathrm{OR} \geq 5.0$ (and where the $95 \%$ CI does not include 1.0) between the presence of cervical pillar hyperplasia (CPH) at specific cervical segments and the presence of degenerative joint disease (DJD) at specific cervical levels in an age and gender-matched population of subjects with and without $\mathrm{CPH}$.

\section{Sample Size Estimate}

A sample size estimate method for the C-coefficient specifically, was not directly available, so the Pearson Rho method was used as a proxy. An estimate was performed using the specifications of $80 \%$ power, $5 \%$ significance, and an estimated correlation coefficient of 0.4 , and revealed that a minimum total sample size of 46 radiographs would be required. The $50 \%$ prevalence at $\mathrm{C} 6$ (approximating the previously reported $46 \%$ prevalence of $\mathrm{CPH}$ at $\mathrm{C} 5$ and $\mathrm{C6}$ ) was assumed to be adequate to sat- isfy the required estimated sample size specifications at each level from $\mathrm{C} 3$ to $\mathrm{C} 6$, even with $\mathrm{CPH}$ generally being somewhat less common at $\mathrm{C} 3$ than at the $\mathrm{C} 5$ and $\mathrm{C} 6 \mathrm{lev}-$ els [3].

Another ex post facto sample size estimate was also performed according to the method of Fleiss [33] for Odds Ratios (OR) in Case Control studies. Using the specifications of $80 \%$ power, $95 \%$ confidence, and a ratio of controls-to-cases of 0.4 , the minimum sample sizes which would render the Odds Ratios (ORs) of 1.9 and 5.0 statistically significant, would be 408 and 80, respectively.

\section{Procedure}

Sets of patient radiographs on file at the HK Lee radiology facility were selected at the Canadian Memorial Chiropractic College in Toronto. Independent Ethics Review Board approval was obtained from the same institution, and permission to access files was obtained from the Dean of Clinical Education, prior to the file selection process. The investigator selecting the cases was blinded to the clinical status of the cases. The inclusion criteria for the radiographs were:

a) the radiographs had to be of good radiological quality (including collimation, penetration, and absence of artifacts);

b) each radiograph had to be of a patient in the age range from 40 to 69 yrs (in order to capture age ranges of subjects from low to high prevalence of DJD);

c) the radiographs could not show evidence of a pathologic condition or abnormality other than signs of osteoarthrosis;

d) the files had to consist of at least three views (considered a set of films): an anteroposterior open mouth (APOM), AP lower cervical and a neutral lateral.

Radiographs were evaluated by the first investigator [MS] until a convenience sample of 240 sets of eligible films was collected: 120 with and 120 without pillar hyperplasia $(\mathrm{CPH})$ at $\mathrm{C6}$; the 'with' and 'without' $\mathrm{CPH}$ films were ageand gender-matched. At the time, it was assumed that this sample would reflect the general adult-population prevalence for cervical pillar hyperplasia of $46 \%$, as reported by Peterson et al [3]. Even if CPH was considered a normal variant due to the high prevalence, it would likely introduce biomechanical stresses at its spinal level. Presence/ absence of hyperplasia was evaluated at each level from C3 to C6 in order to categorize the individual cervical segment as 'hyperplastic' or 'not hyperplastic.' Age was recorded in terms of six 5-yr categories ranging between 40 and 69 years of age. Radiographs were read until each 
age and gender sub-category contained 10 sets of films. The selected sets of films were coded with chronological numbers, and then manually shuffled to randomize their order. When they were subsequently administered to the two assessors, no identifying information was included in the film package.

The presence of pillar hyperplasia $(\mathrm{CPH})$ was evaluated by the first assessor/investigator [MS] from C3 through C6 by drawing lines along the superior and inferior articular surfaces of each pillar on a neutral lateral cervical radiograph. Lines converging posteriorly designated what was considered 'normal' pillar architecture (Figure 1a). Parallel or posteriorly diverging lines designated what has been defined as 'pillar hyperplasia' (Figure 1b) [2-4]. The reliability of this method of measurement has been determined previously to be moderate-to-substantial $[3,4]$. The data were categorical (binary nominal) since each pillar was assigned a label of either 'normal' or 'hyperplastic'. The articular pillars of C7 were not evaluated because of their normally 'notched' appearance [34]. Bony hypertrophy from facet arthrosis was not considered a potential confounder because arthrosis normally occurs on the anterior or posterior margins of the facet, not the superior and inferior surfaces used in the definition of $\mathrm{CPH}$.

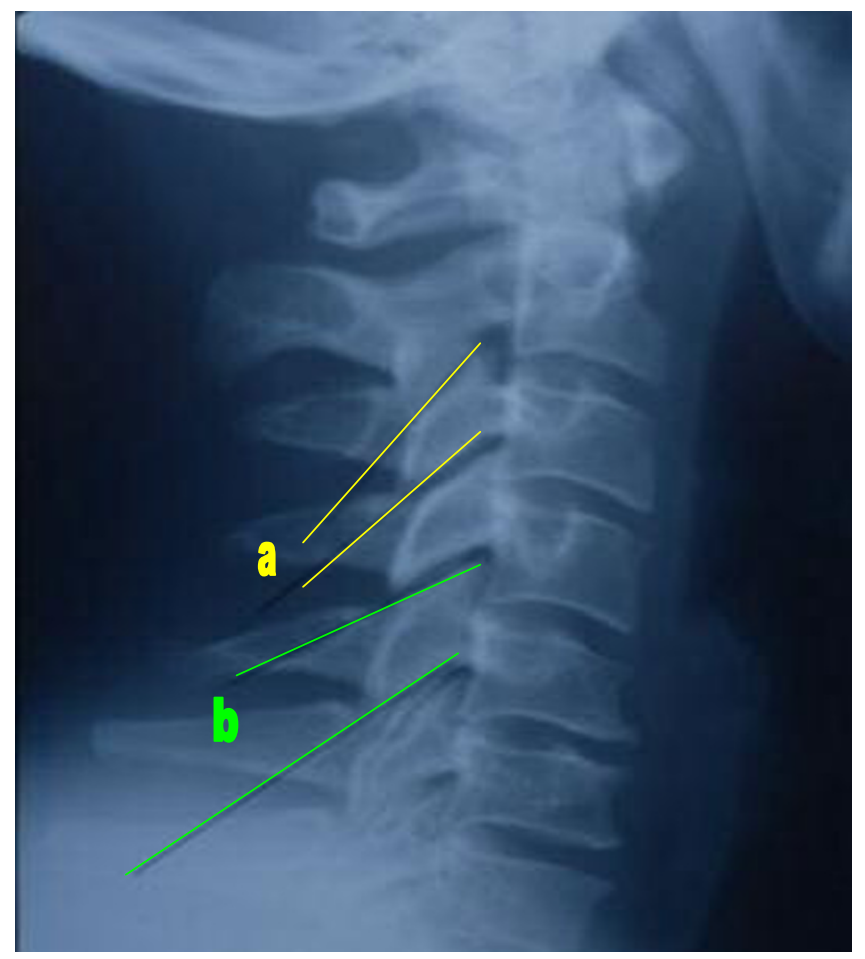

Figure I

Lateral cervical radiograph demonstrating a normal cervical articular pillar (a) and cervical pillar hyperplasia (b). Previously published by the same authors [4].
All 240 sets of films were then reshuffled and re-evaluated for the presence/absence of radiological signs of degenerative joint disease. APOM and AP lower cervical views were used to assess the zygapophyseal joints. Signs of DJD affecting the zygapophyseal joint included subchondral sclerosis, reduction of the joint space, or bony hypertrophy, which result in a disruption of the normally smooth lateral sine curve formed by the external aspect of the articular pillars [18]. Neutral lateral cervical films were used to assess the disc spaces and the presence or absence of anterior or posterior osteophytes. The uncinate processes were not assessed, given that their degenerative changes parallel those of the intervertebral disc [19]. Each radiograph was also evaluated at six levels (from the $\mathrm{C} 1-$ $\mathrm{C} 2$ level to the $\mathrm{C} 6-\mathrm{C} 7$ level) by the second investigator [CP] who was blinded not only to the CPH data collected by the first investigator, but also to any clinical/identifying subject information, and the randomization process. The data were categorical (binary), because each articulation was labelled as either 'normal' or 'showing signs of DJD' (unilateral or bilateral).

\section{Data Analysis}

Statistica software was used to determine the association between segment-specific CPH and DJD via the Contingency Coefficient (C-coefficient) at the 5\% level of significance, where:

$$
\text { C-coefficient }=\sqrt{\{(\text { Chi-square }) /(\text { Chi-square }+n\})}[35] .
$$

SPSS was used to determine the association between segment-specific CPH and DJD via Odds Ratios (OR) and their 95\% Confidence Intervals (95\% CI).

\section{Results}

In our sample, the overall CPH prevalence was 11\%, 11\%, $43 \%$ and 50\% at C3, C4, C5 and C6, respectively. Our initial assumption of achieving approximately the previously reported 46\% prevalence of $\mathrm{CPH}$ was true for $\mathrm{C} 5$ and $\mathrm{C6}$ but the actual prevalence at C3 and C4 was lower. DDD prevalence, in accordance with previous reports, was highest at the C5-6 and C6-7 levels, with our sample prevalence at $\mathrm{C} 2-3, \mathrm{C} 3-4, \mathrm{C} 4-5, \mathrm{C} 5-6$ and $\mathrm{C} 6-7$ being at $4 \%$, $15 \%, 35 \%, 70 \%$, and $47 \%$, respectively. Prevalence of facet degeneration for the same levels was 22\%, 35\%, $35 \%, 35 \%$, and 22\%, respectively.

The C-coefficients and ORs for the segmental relationships between cervical pillar hyperplasia $(\mathrm{CPH})$ and degenerative joint disease (DJD) across all age groups (40-69 years) indicate that the strongest associations of statistical significance occurred at C4 and C5; however, these correlation coefficients and ORs were all considerably weaker than the initially proposed clinically impor- 
tant 'moderate' associations represented by $\mathrm{C} \geq .4$ and $\mathrm{OR}$ $\geq 5.0$ [Table 1 and Table 2].

The strongest overall (i.e. not stratified by age categories) associations were demonstrated between $\mathrm{C} 4 \mathrm{CPH}$ and C4-5 DDD and between C5 CPH and C5-6 DDD: C = .16 $(\mathrm{p}=.012), \mathrm{OR}=2.80(95 \% \mathrm{CI}=1.22-6.42) ; \mathrm{C}=.21(\mathrm{p}=$ $.001), \mathrm{OR}=2.48(95 \% \mathrm{CI}=1.32-4.661)$, respectively. The age-stratified ORs and C-coefficients were similar to the overall levels of association, except between $\mathrm{C} 4 \mathrm{CPH}$ and C3-4 DDD, where the C-coefficients for the 40-54 years of age subgroups were significant (all 3 C-coefficients $>.30$ $(\mathrm{p}<.05))$ but the overall relationship was essentially zero $(\mathrm{C}=.07 ; \mathrm{p}=.252)$ [Table 1]. Generally speaking, however, the ORs tend to corroborate with their corresponding Ccoefficients as far as association strength (effect size) and

Table I: Segmental association between CPH and DJD

\section{C3 Pillars}

\begin{tabular}{|c|c|c|c|c|c|c|}
\hline & $\mathrm{Cl}-2$ & C2-3 IVD & C2-3 Facet & C3-4 IVD & C3-4 Facet & Sample size \\
\hline All ages & $.05(p=.467)$ & $.06(p=.371)$ & $.10(p=.135)$ & $.01(p=.927)$ & $.04(p=.539)$ & 240 \\
\hline $40-44$ & N/A & N/A & $.05(p=.736)$ & $.05(p=.736)$ & $.12(p=.426)$ & 40 \\
\hline $45-49$ & $.09(p=.583)$ & $.25(p=.100)$ & $.30(p=.047)$ & $.02(p=.875)$ & $.00(p=1.00)$ & 40 \\
\hline $50-54$ & $.18(p=.257)$ & N/A & $.08(p=.588)$ & $.18(p=.257)$ & $.02(p=.886)$ & 40 \\
\hline $55-59$ & $.12(p=.426)$ & $.09(p=.583)$ & $.24(p=.118)$ & $.17(p=.27 I)$ & $.04(p=.802)$ & 40 \\
\hline $60-64$ & $.06(p=.679)$ & $.04(p=.816)$ & $.03(p=.826)$ & $.09(p=.583)$ & $.17(p=.26 I)$ & 40 \\
\hline $65-69$ & $.16(p=.315)$ & $.05(p=.738)$ & $.01(p=.962)$ & $.01(p=.926)$ & $.20(p=.206)$ & 40 \\
\hline
\end{tabular}

C4 Pillars

\begin{tabular}{|c|c|c|c|c|c|}
\hline & C3-4 IVD & C3-4 Facet & C4-5 IVD & C4-5 Facet & Sample size \\
\hline All ages & $.07(p=.252)$ & $.06(p=.338)$ & $.16(p=.012)$ & $.09(p=.164)$ & 240 \\
\hline $40-44$ & $.39(p=.007)$ & $.08(p=.588)$ & $.04(p=.782)$ & $.05(p=.738)$ & 40 \\
\hline $45-49$ & $.33(\mathrm{p}=.028)$ & $.30(p=.043)$ & $.09(\mathrm{p}=.559)$ & $.07(p=.64 I)$ & 40 \\
\hline $50-54$ & $.35(\mathrm{p}=.020)$ & $.07(p=.672)$ & $.44(p=.002)$ & $.13(p=.389)$ & 40 \\
\hline $55-59$ & $.17(p=.27 I)$ & $.27(p=.079)$ & $.15(\mathrm{p}=.329)$ & $.27(p=.079)$ & 40 \\
\hline $60-64$ & $.12(p=.426)$ & $.39(p=.006)$ & $.23(p=.132)$ & $.09(p=.586)$ & 40 \\
\hline $65-69$ & $.10(p=.507)$ & $.10(p=.519)$ & $.02(p=.916)$ & $.03(p=.832)$ & 40 \\
\hline
\end{tabular}

\section{C5 Pillars}

\begin{tabular}{lrrrrr}
\hline & C4-5 IVD & C4-5 Facet & C5-6 IVD & C5-6 Facet & Sample size \\
\hline All ages & $.16(p=.009)$ & $.04(p=.499)$ & $.21(p=.001)$ & $.03(p=.594)$ & 240 \\
$40-44$ & $.09(p=.580)$ & $.21(p=.165)$ & $.37(p=.012)$ & $.02(p=.904)$ & 40 \\
$45-49$ & $.09(p=.559)$ & $.10(p=.519)$ & $.17(p=.273)$ & $.01(p=.941)$ & $.06(p=.705)$ \\
$50-54$ & $.30(p=.047)$ & $.06(p=.723)$ & $.26(p=.091)$ & $.08(p=.604)$ & 40 \\
$55-59$ & $.16(p=.292)$ & $.17(p=.279)$ & $.32(p=.030)$ & $.01(p=.949)$ & 40 \\
$60-64$ & $.36(p=.014)$ & $.23(p=.140)$ & $.17(p=.271)$ & $.01(p)$ & 40 \\
$65-69$ & $.10(p=.516)$ & $.05(p=.726)$ & $.02(p=.874)$ & $.15(p=.324)$ & 40
\end{tabular}

\section{C6 Pillars}

\begin{tabular}{|c|c|c|c|c|c|}
\hline & C5-6 IVD & C5-6 Facet & C6-7 IVD & C6-7 Facet & Sample size \\
\hline All ages & $.14(p=.024)$ & $.12(p=.058)$ & $.13(p=.070)$ & $.04(p=.536)$ & 240 \\
\hline $40-44$ & $.05(p=.751)$ & $.07(p=.633)$ & $.11(p=.490)$ & $.16(p=.311)$ & 40 \\
\hline $45-49$ & $.00(p=1.00)$ & $.11(p=.490)$ & $.22(p=.144)$ & $.16(p=.292)$ & 40 \\
\hline $50-54$ & $.16(p=.311)$ & $.06(p=.705)$ & $.05(p=.751)$ & $.12(p=.429)$ & 40 \\
\hline $55-59$ & $.39(p=.008)$ & $.29(p=.056)$ & $.10(p=.507)$ & $.22(p=.144)$ & 40 \\
\hline $60-64$ & $.00(p=1.00)$ & $.10(p=.525)$ & $.10(p=.507)$ & $.11(p=.490)$ & 40 \\
\hline $65-69$ & $.35(p=.018)$ & $.10(p=.525)$ & $.29(p=.058)$ & $.15(p=.342)$ & 40 \\
\hline
\end{tabular}

*IVD $=$ Intervertebral Disc †Bold Type = statistically significant correlation coefficients 
Table 2: Segmental association between CPH and DJD using the odds ratio (5-year age categories)

\section{C3 Pillars}

\begin{tabular}{|c|c|c|c|c|c|c|c|c|c|c|c|}
\hline & \multicolumn{2}{|c|}{$\mathrm{Cl}-2$} & \multicolumn{2}{|c|}{ C2-3 IVD } & \multicolumn{2}{|c|}{$\mathrm{C} 2-3 \mathrm{~F}$} & \multicolumn{2}{|c|}{ C3-4 IVD } & \multicolumn{2}{|c|}{$\mathrm{C} 3-4 \mathrm{~F}$} & \multirow[b]{2}{*}{$\begin{array}{c}\text { Sample } \\
\text { Size }\end{array}$} \\
\hline & OR & $95 \% \mathrm{Cl}$ & OR & $95 \% \mathrm{Cl}$ & OR & $95 \% \mathrm{Cl}$ & OR & $95 \% \mathrm{Cl}$ & OR & $95 \% \mathrm{Cl}$ & \\
\hline overall & N/A & N/A & 2.05 & $.41-10.20$ & 1.92 & $.81-4.57$ & 0.95 & $.31-2.92$ & 1.29 & $.57-2.93$ & 240 \\
\hline $40-44$ & N/A & N/A & N/A & N/A & 0.00 & $\mathrm{~N} / \mathrm{S}$ & 0.00 & $N / S$ & 0.00 & $\mathrm{~N} / \mathrm{S}$ & 40 \\
\hline $45-49$ & 0.00 & $\mathrm{~N} / \mathrm{S}$ & 8.50 & $\begin{array}{c}.44- \\
163.85\end{array}$ & 7.11 & $.83-60.75$ & 1.21 & $.11-12.81$ & 1.00 & $.10-10.41$ & 40 \\
\hline $50-54$ & 4.13 & $.30-56.38$ & N/A & $\mathrm{N} / \mathrm{A}$ & 1.94 & $.17-21.92$ & 4.13 & $.30-56.38$ & 0.84 & $.08-8.66$ & 40 \\
\hline $55-59$ & 0.00 & $N / S$ & 0.00 & $N / S$ & 4.33 & $.62-30.25$ & 0.00 & $N / S$ & 1.28 & $.19-8.72$ & 40 \\
\hline $60-64$ & 0.00 & $N / S$ & 0.00 & $\mathrm{~N} / \mathrm{S}$ & 1.38 & $.08-23.67$ & 0.00 & $N / S$ & 2380.39 & $N / S$ & 40 \\
\hline $65-69$ & 0.00 & $\mathrm{~N} / \mathrm{S}$ & 1.50 & $.14-16.32$ & 1.05 & $.17-6.60$ & 0.92 & $.15-5.76$ & 3.95 & $.42-37.49$ & 40 \\
\hline
\end{tabular}

\section{C4 Pillars}

\begin{tabular}{|c|c|c|c|c|c|c|c|c|c|}
\hline & \multicolumn{2}{|c|}{ C3-4 IVD } & \multicolumn{2}{|c|}{$\mathrm{C} 3-4 \mathrm{~F}$} & \multicolumn{2}{|c|}{ C4-5 IVD } & \multicolumn{2}{|c|}{ C4-5 F } & \multirow[b]{2}{*}{ Sample Size } \\
\hline & OR & $95 \% \mathrm{Cl}$ & OR & $95 \% \mathrm{Cl}$ & OR & $95 \% \mathrm{Cl}$ & OR & $95 \% \mathrm{Cl}$ & \\
\hline overall & 1.77 & $.66-4.76$ & 0.64 & $.26-1.60$ & 2.81 & $\begin{array}{l}1.22- \\
6.42\end{array}$ & 0.51 & $.20-1.33$ & 240 \\
\hline $40-44$ & $\begin{array}{c}135482.5 \\
0\end{array}$ & $N / S$ & 1.94 & $.17-21.92$ & 0.72 & $.07-7.34$ & 1.50 & $.14-16.32$ & 40 \\
\hline $45-49$ & 7379.52 & $N / S$ & 6133.63 & $\mathrm{~N} / \mathrm{S}$ & 0.00 & $\mathrm{~N} / \mathrm{S}$ & 0.00 & $N / S$ & 40 \\
\hline $50-54$ & 12.80 & $\begin{array}{l}.97- \\
168.70\end{array}$ & 1.49 & $.24-9.35$ & 18.74 & $\begin{array}{l}1.95- \\
179.83\end{array}$ & 0.38 & $.04-3.61$ & 40 \\
\hline $55-59$ & 0.00 & $N / S$ & 0.00 & $N / S$ & 2.54 & $.37-17.25$ & 0.00 & $N / S$ & 40 \\
\hline $60-64$ & 0.00 & $N / S$ & 0.00 & $\mathrm{~N} / \mathrm{S}$ & 5.31 & $.50-56.39$ & 0.57 & $.07-4.50$ & 40 \\
\hline $65-69$ & 2.00 & $.25-15.99$ & 2.14 & $.20-22.65$ & 1.12 & $.14-8.82$ & 0.80 & $.10-6.32$ & 40 \\
\hline
\end{tabular}

\section{C5 Pillars}


Table 2: Segmental association between CPH and DJD using the odds ratio (5-year age categories) (Continued)

\begin{tabular}{|c|c|c|c|c|c|c|c|c|c|}
\hline & \multicolumn{2}{|c|}{ C4-5 IVD } & \multicolumn{2}{|c|}{$\mathrm{C} 4-5 \mathrm{~F}$} & \multicolumn{2}{|c|}{ C5-6 IVD } & \multicolumn{2}{|c|}{$\mathrm{C} 5-6 \mathrm{~F}$} & \multirow[b]{2}{*}{ Sample Size } \\
\hline & OR & $95 \% \mathrm{Cl}$ & OR & $95 \% \mathrm{Cl}$ & OR & $95 \% \mathrm{Cl}$ & OR & $95 \% \mathrm{Cl}$ & \\
\hline overall & 1.90 & $\begin{array}{l}1.08- \\
3.34\end{array}$ & 0.83 & $.49-1.42$ & 2.48 & $\begin{array}{c}1.32- \\
4.66\end{array}$ & 0.98 & $.56-1.73$ & 240 \\
\hline $40-44$ & 1.50 & $.36-6.32$ & 0.23 & $.02-2.13$ & 5.49 & $\begin{array}{l}1.39- \\
21.59\end{array}$ & 0.89 & $.13-6.00$ & 40 \\
\hline $45-49$ & 1.56 & $.35-6.88$ & 1.73 & $.32-9.17$ & 2.29 & $.51-10.28$ & 1.06 & $0.25-4.45$ & 40 \\
\hline $50-54$ & 4.00 & $.98-16.27$ & 1.29 & $.32-5.17$ & 3.27 & $.80-13.35$ & 0.75 & $.17-3.33$ & 40 \\
\hline $55-59$ & 2.00 & $0.55-7.31$ & 0.47 & $.12-1.88$ & 8993.20 & $N / S$ & 1.40 & $.39-5.00$ & 40 \\
\hline $60-64$ & 5.34 & $\begin{array}{l}1.35- \\
21.14\end{array}$ & 0.38 & $.10-1.40$ & 2.33 & $.50-10.77$ & 0.96 & $.27-3.36$ & 40 \\
\hline $65-69$ & 0.66 &. $\mid 9-2.31$ & 1.25 & $.36-4.36$ & 0.88 & $.19-4.16$ & 1.89 & $.53-6.69$ & 40 \\
\hline
\end{tabular}

\section{C6 Pillars}

\begin{tabular}{|c|c|c|c|c|c|c|c|c|c|}
\hline & \multicolumn{2}{|c|}{ C5-6 IVD } & \multicolumn{2}{|c|}{$\mathrm{C} 5-6 \mathrm{~F}$} & \multicolumn{2}{|c|}{ C6-7 IVD } & \multicolumn{2}{|c|}{ C6-7 F } & \multirow[b]{2}{*}{ Sample Size } \\
\hline & OR & $95 \% \mathrm{Cl}$ & OR & $95 \% \mathrm{Cl}$ & OR & $95 \% \mathrm{Cl}$ & OR & $95 \% \mathrm{Cl}$ & \\
\hline overall & 1.90 & $\begin{array}{c}1.08- \\
3.34\end{array}$ & 1.69 & $.96-2.96$ & 1.60 & $.96-2.67$ & 1.21 & $.66-2.22$ & 240 \\
\hline $40-44$ & 1.22 & $.35-4.23$ & 1.59 & $.24-10.70$ & 1.62 & $.4 \mathrm{I}-6.34$ & 0.00 & $N / S$ & 40 \\
\hline $45-49$ & 1.00 & $.27-3.67$ & 1.62 & $.41-6.34$ & 3.05 & $.66-14.13$ & 3.35 & $.32-35.36$ & 40 \\
\hline $50-54$ & 2.00 & $.52-7.72$ & 1.33 & $0.30-5.92$ & 0.82 & $.24-2.83$ & 1.89 & $.38-9.27$ & 40 \\
\hline $55-59$ & 31431.80 & $N / S$ & 3.50 & $.94-12.97$ & 1.56 & $.42-5.76$ & 0.33 & $.07-1.52$ & 40 \\
\hline $60-64$ & 1.00 & $.24-4.18$ & 1.50 & $.43-5.25$ & 1.56 & $.42-5.76$ & 1.62 & $.4 \mathrm{I}-6.34$ & 40 \\
\hline $65-69$ & 10.23 & $\begin{array}{l}1.12- \\
93.34\end{array}$ & 1.5 & $.43-5.25$ & 4.83 & $.86-27.22$ & 1.83 & $.52-6.43$ & 40 \\
\hline
\end{tabular}

*IVD $=$ Intervertebral Disc †Bold Type $=$ statistically significant odds ratios 
inferability (statistical significance) are concerned [Table 2].

The stratified associations of statistical significance were mostly demonstrated between $\mathrm{C} 4$ and $\mathrm{C} 5 \mathrm{CPH}$ and the adjacent level DDD, except in the oldest age subgroup (65-69 yrs) [Table 1 and Table 3]. Pillar hyperplasia at C4 and C4-5 DDD in the 50-54 years of age category demonstrated the strongest association: $\mathrm{C}=.44(\mathrm{p}=.002)$, OR $=18.74(95 \% \mathrm{CI}=1.95-179.83)$ [Table 1 and Table 2 ].
Only two older subgroups demonstrated moderatelystrong and statistically significant associations, and these were between C6 CPH and C5-6 DDD for the 55-59 and 65-69 yr old subgroups: $\mathrm{C}=.39(\mathrm{p}=.008), \mathrm{OR}=31431.8$ $\left(95 \% \mathrm{CI}=0.0-1.11 \times 10^{56}\right) ; \mathrm{C}=.35(\mathrm{p}=.018), \mathrm{OR}=$ $10.23(95 \% \mathrm{CI}=1.12-93.34)$, respectively; but this relationship did not consistently apply to the younger subgroups. Less strong, but also statistically significant, were the relationships between $\mathrm{C} 5 \mathrm{CPH}$ and $\mathrm{C} 4-5 \mathrm{DDD}$ in the 60-64 yrs of age subgroup, and between C5 CPH and C56 DDD in the 55-59 yrs of age subgroup: $\mathrm{C}=.36(\mathrm{p}=$

Table 3: Segmental association between CPH and DJD using the odds ratio(10-year age-categories)

\begin{tabular}{|c|c|c|c|c|c|c|c|c|c|c|c|}
\hline \multicolumn{12}{|c|}{ C3 Pillars } \\
\hline & \multicolumn{2}{|c|}{$\mathrm{Cl}-2$} & \multicolumn{2}{|c|}{ C2-3 IVD } & \multicolumn{2}{|c|}{$C 2-3 F$} & \multicolumn{2}{|c|}{ C3-4 IVD } & \multicolumn{2}{|c|}{$\mathrm{C} 3-4 \mathrm{~F}$} & \multirow[b]{2}{*}{ Sample Size } \\
\hline & OR & $95 \% \mathrm{Cl}$ & OR & $95 \% \mathrm{Cl}$ & OR & $95 \% \mathrm{Cl}$ & OR & $95 \% \mathrm{Cl}$ & OR & $95 \% \mathrm{Cl}$ & \\
\hline overall & $\mathrm{N} / \mathrm{A}$ & N/A & 2.05 & $.41-10.20$ & 1.92 & $.81-4.57$ & 0.95 & $.31-2.92$ & 1.29 & $.57-2.93$ & 240 \\
\hline $40-49$ & 0.00 & N/A & 8.75 & $.50-|53.8|$ & 4.79 & $.74-30.97$ & 1.14 & $.12-10.53$ & 0.62 & $.07-5.38$ & 80 \\
\hline $50-59$ & 1.19 & $.12-11.01$ & 0.00 & $N / S$ & 2.92 & $.72-11.87$ & 0.75 & $.08-6.67$ & 1.07 & $.25-4.56$ & 80 \\
\hline $60-69$ & 0.00 & $N / S$ & 1.19 & $.19-18.78$ & 1.00 & $.22-4.52$ & 1.08 & $.20-5.85$ & 4.99 & $.58-42.69$ & 80 \\
\hline
\end{tabular}

C4 Pillars

\begin{tabular}{|c|c|c|c|c|c|c|c|c|c|}
\hline & \multicolumn{2}{|c|}{ C3-4 IVD } & \multicolumn{2}{|c|}{$\mathrm{C} 3-4 \mathrm{~F}$} & \multicolumn{2}{|c|}{ C4-5 IVD } & \multicolumn{2}{|c|}{ C4-5 F } & \multirow[b]{2}{*}{ Sample Size } \\
\hline & OR & $95 \% \mathrm{Cl}$ & OR & $95 \% \mathrm{Cl}$ & OR & $95 \% \mathrm{Cl}$ & OR & $95 \% \mathrm{Cl}$ & \\
\hline overall & 1.77 & $.66-4.76$ & 0.64 & $.26-1.60$ & 2.81 & $1.22-6.42$ & 0.51 & $.20-1.33$ & 240 \\
\hline $40-49$ & 5.67 & $.85-37.56$ & 2.86 & $.47-17.57$ & 0.58 & $.06-5.27$ & 1.03 & $.11-9.65$ & 80 \\
\hline $50-59$ & 1.50 & $.28-8.11$ & 0.45 & $.09-2.22$ & 6.71 & $1.65-27.34$ & 0.17 & $.02-1.37$ & 80 \\
\hline $60-69$ & 1.08 & $.20-5.85$ & 0.34 & $.07-1.53$ & 2.33 & $.52-10.52$ & 0.67 & $.16-2.9 \mid$ & 80 \\
\hline
\end{tabular}

C5 Pillars

\begin{tabular}{|c|c|c|c|c|c|c|c|c|c|}
\hline & \multicolumn{2}{|c|}{ C4-5 IVD } & \multicolumn{2}{|c|}{ C4-5 F } & \multicolumn{2}{|c|}{ C5-6 IVD } & \multicolumn{2}{|c|}{ C5-6 F } & \multirow[b]{2}{*}{ Sample Size } \\
\hline & OR & $95 \% \mathrm{Cl}$ & OR & $95 \% \mathrm{Cl}$ & OR & $95 \% \mathrm{Cl}$ & OR & $95 \% \mathrm{Cl}$ & \\
\hline overall & 1.90 & $1.08-3.34$ & 0.83 & $.49-1.42$ & 2.48 & $1.32-4.66$ & 0.98 & $.56-1.73$ & 240 \\
\hline $40-49$ & 1.52 & $.54-4.25$ & 0.70 & $.20-2.51$ & 3.23 & $1.2 \mid-8.62$ & 0.87 & $.29-2.71$ & 80 \\
\hline $50-59$ & 2.67 & $1.05-6.77$ & 0.74 & $.28-1.94$ & 4.14 & $1.23-13.90$ & 0.97 & $.38-2.45$ & 80 \\
\hline $60-69$ & 1.78 & $.73-4.35$ & 0.70 & $.28-1.71$ & 1.47 & $.50-4.30$ & 1.35 & $.56-3.27$ & 80 \\
\hline
\end{tabular}

C6 Pillars

\begin{tabular}{|c|c|c|c|c|c|c|c|c|c|}
\hline & \multicolumn{2}{|c|}{ C5-6 IVD } & \multicolumn{2}{|c|}{$\mathrm{C} 5-6 \mathrm{~F}$} & \multicolumn{2}{|c|}{ C6-7 IVD } & \multicolumn{2}{|c|}{ C6-7 F } & \multirow[b]{2}{*}{ Sample Size } \\
\hline & OR & $95 \% \mathrm{Cl}$ & OR & $95 \% \mathrm{Cl}$ & OR & $95 \% \mathrm{Cl}$ & OR & $95 \% \mathrm{Cl}$ & \\
\hline overall & 1.90 & $1.08-3.34$ & 1.69 & $.96-2.96$ & 1.60 & $.96-2.67$ & 1.21 & $.66-2.22$ & 240 \\
\hline $40-49$ & 1.11 & $.46-2.68$ & 1.57 & $.53-4.65$ & 2.15 & $.78-5.92$ & 1.54 & $.24-9.75$ & 80 \\
\hline 50-59 & 3.77 & $1.20-11.79$ & 2.22 & $.86-5.74$ & 1.11 & $.46-2.68$ & 0.75 & $.26-2.15$ & 80 \\
\hline $60-69$ & 2.43 & $.81-7.29$ & 1.49 & $.62-3.60$ & 2.05 & $.84-5.04$ & 1.70 & $.68-4.22$ & 80 \\
\hline
\end{tabular}

*IVD = Intervertebral Disc †Bold Type = statistically significant odds ratios 
$.014), \mathrm{OR}=5.343(95 \% \mathrm{CI}=1.35-21.14) ;$ and $\mathrm{C}=.32(\mathrm{p}$ $=.03), \mathrm{OR}=8993.2\left(95 \% \mathrm{CI}=0.0-8.1 \times 10^{38}\right)$, respec tively [Table 1 and Table 2].

Several discrepancies between the two analyses (C-coefficient vs OR) occurred. Since these may have been due (in part) to underpowered age-subgroup sample sizes, the data were also analyzed using broader 10-year age categories; this helped to elevate the subgroup sample sizes towards the more desirable ' $n=80$ ' suggested by our sample size estimate. These results are presented in Table 3. The findings here demonstrate a similar pattern to the overall OR results, with the strongest stratified association evident between C4 CPH and C4-5 DDD in the 50-59 age-category: $\mathrm{OR}=6.71(95 \% \mathrm{CI}=1.65-27.34)$. Statistically-significant associations are also evident between $\mathrm{C5}$ CPH and C4-5 DDD and between C5 CPH and C5-6 DDD both overall, and in the 40-59 age-categories [Table $3]$. In general, however, most associations between segmental $\mathrm{CPH}$ and adjacent level facet degeneration were not statistically or clinically significant.

\section{Discussion}

The only known clinically relevant result of cervical pillar hyperplasia, as demonstrated in the literature, is its straightening effect on the cervical spine lordosis $[2,3]$. Therefore, with such little research on what effect cervical pillar hyperplasia may potentially have on cervical spine biomechanics, it is important to explore any possible clinical consequences of this condition. In our preliminary study [4], we assessed the possibility that altered spinal biomechanics due to $\mathrm{CPH}$ may lead to degenerative changes.

Our present study suggests that a generally weak-to-moderate segmental association exists between C4 and C5 $\mathrm{CPH}$ and adjacent level degenerative disc disease (DDD), with the strongest (overall) association demonstrated between C5 CPH and C5-6 DDD. The odds of segmental DDD occurring together with the adjacent presence of $\mathrm{CPH}$ for the overall age-categories are approximately twoto-one. Age-stratified results demonstrated the same pattern of association (with one exception), even reaching the initially hypothesized moderately-strong association levels of $\mathrm{C}=0.4$ and $\mathrm{OR}>5.0$, in some age categories [Table 1, 2, 3]. Pillar hyperplasia at C4 and C4-5 DDD in the 50-54 year age category had the strongest stratified association; nevertheless, generally, the segmental relationship between CPH and DJD did not reach the initially proposed association of clinical importance $(C>.4$ and OR > 5.0) across all age categories.

As mentioned previously, the discrepancies between the $\mathrm{C}$-coefficients and ORs in the younger age subgroups (e.g. 40-54 years) for $\mathrm{C} 4 \mathrm{CPH}$ and $\mathrm{C} 3-4$ DDD may be due to sample size and/or CPH and DJD prevalence inadequacies; these, in turn, can sometimes amplify limitations of the computational formulas themselves. More specifically, naturally occurring low pillar hyperplasia prevalence at C3 and low DJD prevalence in adjacent segments, were likely the cause of the lack of statistically significant associations at those respective levels, which in turn, may be due to the likelihood that there are other known contributors to the development of DJD; these include trauma, genetic, metabolic, and inflammatory processes [18-20,23], but they were not tested in our study. Nevertheless, our results suggest that cervical pillar hyperplasia $(\mathrm{CPH})$ is only weakly-to-moderately correlated with the presence of degenerative joint disease; therefore, it may contribute somewhat to the development of DJD, but the body may also compensate to some extent for the changes resulting from its slightly aberrant biomechanics. Considering that there are likely several clinically important contributing factors leading to the development of degenerative joint disease, hyperplasia may be but one of several of these. Our findings, when subjected to Coefficient of Determination analysis, suggest that at least in some cervical-spine levels, and in some age categories, CPH may contribute to approximately $9-18 \%(\mathrm{p} \leq .05)$ of the development of DJD [35].

Some limitations encountered in this study were poor visualization of $\mathrm{C} 2-3$ when assessing films for $\mathrm{CPH}$ and DJD, poor visualization of C1-2 while assessing for DJD, and the sometimes inconsistent presence of hyperplasia in the right and left pillar at a single cervical level. Due to diverging rays of the $\mathrm{x}$-ray beam and small variances in patient positioning, the two articular pillars at any particular level may not be perfectly superimposed on the lateral cervical radiograph, thus allowing the evaluation of each pillar separately for $\mathrm{CPH}$. We were also limited by the lack of any peer-reviewed literature confirming the reliability of evaluating DJD severity. Another potential assessment bias in the present study was the fact that one of the assessors, an experienced radiologist, could not be blinded to the presence/absence of cervical pillar hyperplasia while assessing for DJD. A future study could eliminate this bias by blinding the assessing radiologist to the purpose of the study.

Another limitation is that the OR sample size estimate was performed ex post facto (after the data were collected), and this, as well as the data analysis (the hypothesis testing part) itself, revealed that the sample sizes in most of the age-specific categories were too small to yield adequate $(\geq 80 \%)$ power i.e. statistical significance. Age categories were combined in an attempt to compensate for this, but future studies should endeavour to collect larger samples. 


\section{Conclusion}

Our study suggests that cervical pillar hyperplasia (CPH) is weakly-to-moderately associated with the presence of degenerative joint disease (the DDD component of DJD); more specifically, an approximate two-to-one odds, or a weak-to-moderate association exists between $\mathrm{C} 4$ and $\mathrm{C} 5$ $\mathrm{CPH}$ and adjacent level degenerative disc disease (DDD), with the strongest (overall) associations occurring between $\mathrm{C} 4 \mathrm{CPH}$ and $\mathrm{C} 4-5$ DDD and between $\mathrm{C} 5 \mathrm{CPH}$ and C5-6 DDD. Coefficients of Determination of 0.09-0.18 suggest that at some cervical-spine levels, and in some age categories, CPH may contribute to approximately $9-18 \%$ ( $\mathrm{p} \leq .05)$ of the development/etiology of DJD. Therefore, while $\mathrm{CPH}$ may be but one of many contributing factors to the development of cervical-spine degeneration, chiropractic clinicians, who are actively treating patients, need to be aware of all conditions, including $\mathrm{CPH}$, that may influence their patients' clinical presentations, susceptibility/response to available treatments, and their prognostic factors. Finally, we also hypothesize that the correlations between level-specific CPH and DJD may be more meaningful when the severity of DJD is also factored into the analysis, and we therefore recommend that future research consider this.

\section{Competing interests}

The author(s) declare that they have no competing interests.

\section{Authors' contributions}

MS participated in the design of the study, the acquisition, analysis and interpretation of data and she drafted the manuscript.

CP conceived of the study concept, participated in the acquisition of the data and helped to draft the manuscript.

\section{Acknowledgements}

We would like to thank the ACC Research Scholarship Committee for selecting this project for the ACC Research Scholarship Award. We would also like to thank Carol Hagino for her statistical expertise and her commitment in providing support on this research study. As well, we would like to thank the CMCC HK Lee Clinic for permitting us access to the necessary radiology files. The authors were unable to locate the patients featured in the de-identified radiograph (Figure I), so consent was not obtained from the patients or their relatives for publication of the study.

\section{References}

I. McRae J: Roentgenometrics in chiropractic Toronto: Canadian Memorial Chiropractic College; 1977.

2. Peterson CK, Wei T: Vertical hyperplasia of the cervical articular pillars. Another look at the straight cervical spine. J Chiropractic 1987, $21: 78-9$.

3. Peterson CK, Kirk RJ, Isdahl M, Humphrey BK: Prevalence of hyperplastic articular pillars in the cervical spine and relationship with cervical lordosis. J Manipulative Physiol Ther 1999, 22:390-4.

4. Stupar M, Mauron D, Peterson C: Inter-examiner reliability of the diagnosis of cervical pillar hyperplasia (CPH), and the correlation between $\mathrm{CPH}$ and spinal degenerative joint disease (DJD). BMC Musculoskelet Disord 2003, 4:28.

5. Harrison DE, Harrison DD, Haas JW, Janik TJ, Holland B: Do sagittal plane anatomical variations (angulation) of the cervical facets and $\mathrm{C2}$ odontoid affect the geometrical configuration of the cervical lordosis? Clin Anat 2005, I 8: I04- I I I.

6. Harrison DE, Harrison DD, Troyanovich DC: Reliability of spinal displacement analysis on plain x-rays: a review of commonly accepted facts and fallacies with implications for chiropractic education and technique. J Manipulative Physiol Ther 1998, 21:252-66.

7. Harrison DD, Harrison DE, Troyanovich SJ, Harrison SO: Letter to the editor. Prevalence of hyperplastic articular pillars in the cervical spine and relationship with cervical lordosis. J Manipulative Physiol Ther 2000, 23(5):366-8.

8. Haas M, Taylor JAM, Gillette RG: The routine use of radiographic spinal displacement analysis: a dissent. J Manipulative Physio Ther 1999, 22:254-9.

9. Peterson CK: In response. J Manipulative Physiol Ther 2000, 23(5):368-9.

10. Maurel N, Lavaste F, Skalli W: A three-dimensional parameterized finite element model of the lower cervical spine. Study of the influence of the posterior articular facets. J Biomech 1997, 30(9):921-31.

II. Pal GP, Routal RV, Saggu SK: The orientation of the articular facets of the zygapophysial joints at the cervical and upper thoracic region. Journal Anat 200I, 198:43I-4I.

12. Kumaresan S, Yoganandan N, Pintar FA, Maiman DJ, Goel VK: Contribution of disc degeneration to osteophyte formation in the cervical spine: a biomechanical investigation. J Orthop Res 200I, 19:977-984.

13. Pellengahr C, Pfahler M, Kuhr M, Hohmann D: Influence of facet joint angle and asymmetric disc collapse on degenerative olisthesis of the cervical spine. Orthopedics 2000, 23:697-70I.

14. Pal GP, Sherk HH: The vertical stability of the cervical spine. Spine 1988, 5:447-9.

15. Yoganandan N, Kumaresan S, Pintar FA: Biomechanics of the cervical spine part 2. Cervical spine soft tissue response and biomechanical modeling. Clin Biomech 200I, 16:I-27.

16. Hilibrand AS, Robbins M: Adjacent segment degeneration and adjacent segment disease: the consequences of spinal fusion? Spine J 2004, 4:S190-4.

17. Gay RE: The curve of the cervical spine: variations and significance. J Manipulative Physiol Ther 1993, 16:591-4.

18. Resnick D, Niwayama G: Diagnosis of bone and joint disorder Volume 2. Philadelphia (PA): W.B. Saunders Company; 2002

19. Yochum TR, Rowe LJ: Essentials of Skeletal Radiology 3rd edition. Baltimore: William \& Wilkins; 2004.

20. McClure $P:$ The degenerative cervical spine: pathogenesis and rehabilitation concepts. J Hand Ther 2000:163-74.

21. Prescher A: Anatomy and pathology of the aging spine. Eur J Radiol 1998, 27(3): |81-95.

22. Côté P, Cassidy JD, Yong-Hing K, Sibley J, Loewy J: Apophysial joint degeneration, disc degeneration and sagittal curve of the spine. Spine 1997, 22:859-64.

23. Zhang W, Doherty M: How important are genetic factors in osteoarthritis? Contributions from family studies. J Rheum 2005, 32(6): I I39-42.

24. Harding JG: Complications of cervical arthritis. Postgrad Med 1992, 9 1(4):309-18.

25. Lestini WF, Wiesel SW: The pathogenesis of cervical spondylosis. Clin Orthop Relat Res 1989, 239:69-93.

26. Yoskovitch A, Kantor S: Cervical osteophytes presenting as unilateral vocal fold paralysis and dysphasia. J Laryngol Otol 200I, I I 5:422-24.

27. Gore DR: Roentgenographic findings in the cervical spine in asymptomatic persons: a ten-year follow-up. Spine 200I, 26:2463-6.

28. Guyer RD, Mason SL, Ohnmeiss DD: The relation between cervical discographic pain responses and radiographic images. Clin J Pain 2000, I 6(1): I-5

29. Peterson CK, Bolton J, Wood A, Humphreys BK: A cross-sectional study correlating degeneration of the cervical spine with disability and pain in United Kingdom patients. Spine 2003, 28(2):129-33 
30. Roh JS, Teng AL, Yoo JU, Davis J, Furey C, Bohlman HH: Degenerative disorders of the lumbar and cervical spine. Orthop Clin $\mathrm{N}$ Am 2005, 36(3):255-62.

3I. Marchiori DM, Handerson CMR: A cross-sectional study correlating cervical radiographic degenerative findings to pain and disability. Spine 1996, 2 I:2747-5I.

32. Cook J, Peterson CK: Intervertebral disc, apophysial and uncovertebral joint degeneration in the cervical spine: reliability of radiological diagnosis [abstract]. European Journal of Chiropractic 2003, 48(2):63.

33. Open Source Statistics for Public Health [http:// www.openepi.com/SampleSize/SSCC.htm]

34. Keats TE: Atlas of Normal Roentgen Variants that may Simulate Disease St. Louis (MO): Mosby Year Book, Inc; 1991.

35. Norman GR, Streiner DL: Biostatistics: The Bare Essentials Hamilton: B.C. Decker; 1998.

Publish with Biomed Central and every scientist can read your work free of charge

"BioMed Central will be the most significant development for disseminating the results of biomedical research in our lifetime. "

Sir Paul Nurse, Cancer Research UK

Your research papers will be:

- available free of charge to the entire biomedical community

- peer reviewed and published immediately upon acceptance

- cited in PubMed and archived on PubMed Central

- yours - you keep the copyright

Submit your manuscript here:

http://www.biomedcentral.com/info/publishing_adv.asp
BioMedcentral 